\title{
LAS DIFICULTADES DE LA ADMINISTRACIÓN CONCURSAL EN LOS CONCURSOS DE ENTIDADES DEPORTIVAS
}

\author{
THE DIFFICULTIES OF THE BANKRUPTCY ADMINISTRATION IN THE \\ ARRENGEMENTS WITH CREDITORS OF SPORTS ENTITIES
}

\author{
CÉSAR GILO GÓMEZ \\ Doctor en Derecho. Universidad de Salamanca \\ Abogado \\ cesargilo@usal.es
}

\begin{abstract}
Resumen:
En las siguientes líneas se analiza la complicada labor encomendada a la Administración Concursal en aquellos procedimientos judiciales en los que el deudor declarado en concurso es una entidad deportiva. Para ello, tomando como base las limitaciones patrimoniales del deudor establecidas en la normativa concursal dependiendo de si sus facultades han sido suspendidas o meramente intervenidas, se estudia la especialidad del mandato encomendado a la Administración Concursal en procedimientos concursales de deudores con un objeto social tan particular.

De igual manera, se examina el estudio de las decisiones que la Administración Concursal debe adoptar para garantizar la continuidad de la actividad de la entidad, con todas las implicaciones que ello conlleva en cuanto a la necesaria intervención de los poderes públicos y la masa social propia del club en los acuerdos que puedan alcanzarse, con apoyo en los precedentes judiciales existentes.

Todo ello dibuja un complicado escenario que exigirá de la Administración Concursal un comportamiento acorde con un alto grado de diligencia profesional que le permita aunar los distintos intereses en juego y que representa la situación actual de muchas instituciones deportivas en la actualidad.
\end{abstract}

Palabras clave: Ley Concursal, deporte, Administración Concursal, deudor, diligencia.

\begin{abstract}
:
In the following lines there is analyzed the complicated labor entrusted the Bankruptcy administration in those judicial procedures in which the debtor declared in contest is a sport entity. For it, taking as a base the patrimonial limitations of the debtor established in the Bankruptcy Act depending on if his powers have been suspended or merely controlled, there is studied the speciality of the mandate entrusted the Bankruptcy administration in procedures compete for them of debtors with such a particular corporate purpose.

Of equal way, there is examined the study of the decisions that the Bankruptcy administration must adopt to guarantee the continuity of the activity of the entity, with all the implications that it carries as for the necessary intervention of the public power and the social own mass of the club in the agreements that could be reached, with support in the judicial precedents.
\end{abstract}

REJIE Nueva época: Revista Jurídica de Investigación e Innovación Educativa Núm.19, Enero 2019, pp. 101-114

[En línea] http://www.revistas.uma.es/index.php/rejie

Recibido: mayo 2018

Aceptado: octubre 2018 
All this draws a complicated scene that will demand of the Bankruptcy administration a behavior according to a high degree of professional diligence that allows him to unite the different interests in game and that represents the current situation of many sports institutions at present.

Keywords: Bankruptcy Act, sport, Bankruptcy administration, debtor, diligence.

SUMARIO: 1. Introducción. 2. Intervención de las facultades de la entidad deportiva. 3. Suspensión de las facultades de la entidad deportiva. 4. Decisiones que debe adoptar la Administración Concursal para garantizar la continuidad de la actividad de la entidad deportiva. 5. Confección del informe de los artículos 74 y 75 de la Ley Concursal. 6. Convenios suscritos por las entidades deportivas. 7. La liquidación de las entidades deportivas. 8. Fase de calificación. 9. Conclusiones. Bibliografía.

\section{Introducción.}

La declaración de concurso de una persona física o jurídica conlleva que la Administración Concursal designada en el procedimiento judicial realice cierta labor de acercamiento previo a la actividad económica que desarrolla el deudor en concurso con el propósito de conocer su actividad, entender sus problemas y poder estudiar las mejores soluciones para la situación de crisis en la que éste se encuentra.

Cuando la actividad del concursado es la participación en competiciones deportivas, la Administración Concursal es colocada en una situación donde, además de tener que adoptar medidas de índole empresarial para la continuación de la actividad económica del deudor en un ámbito tan específico como el deportivo, sus decisiones van a verse condicionadas por los propios resultados que consiga el club concursado en las competiciones en las que participe, elemento puramente aleatorio que no depende del órgano concursal. Además de todo ello, debe sumarse el factor social que todo equipo deportivo lleva consigo y que incide de forma inmediata en la masa social y en el tejido empresarial vinculado a referida entidad deportiva ${ }^{1}$.

\section{Intervención de las facultades de la entidad deportiva.}

Uno de los escenarios ante el que puede encontrarse la Administración Concursal designada en un procedimiento donde el deudor sea una entidad deportiva es aquel en el que las facultades del deudor hayan sido intervenidas, conservando por tanto el mismo sus facultades patrimoniales con la autorización o conformidad de la Administración

\footnotetext{
${ }^{1}$ En relación al concepto de entidad deportiva, vid. PALOMAR OLMEDA, A., «La insolvencia de las entidades deportivas profesionales» en CAMPUZANO, A., SANJUÁN Y MUÑOZ, E., (Dirs.) El Derecho de la Insolvencia, Tirant lo Blanch, Valencia, 2016, p. 162, quien las define como un conjunto de entidades entre las que están las Federaciones deportivas, las Ligas profesionales, los clubes y las sociedades anónimas deportivas, además de las formalmente consideradas como tal en fútbol y baloncesto.
} 
Concursal, de acuerdo a lo establecido en el artículo 40 de la Ley 22/2003, de 9 de julio, Concursal $^{2}$ - en adelante $\mathrm{LC}$ - .

En el supuesto de que el concursado sea una institución deportiva, ello conlleva que el órgano de la Administración Concursal sea el encargado de dar el visto bueno a las operaciones que pretenda llevar a cabo el $\mathrm{club}^{3}$, lo que implica que en muchas ocasiones no sólo tenga que autorizar decisiones de pura gestión ordinaria del mismo, sino que también deberá permitir o denegar motivadamente decisiones del deudor relacionadas con su objeto social, como son todas aquellas que tienen que ver con inversiones para la planificación deportiva de la temporada, lo que supone por parte de la Administración Concursal un importante esfuerzo extra de cara a comprender no solo las necesidades financieras de la entidad, sino también las relativas a un fin social tan particular como es la participación en competiciones deportivas.

Derivado de esta especial actividad del deudor, en ocasiones los Juzgados han venido optando de forma prudente por el régimen de intervención más que por el de suspensión de las facultades del deudor para así facilitar de alguna forma la labor de la Administración Concursal ante la peculiaridad que presenta la gestión de una entidad deportiva ${ }^{4}$. Si bien, nada impide que el Juez posteriormente y en función de los hechos que se vayan conociendo del examen de la contabilidad del club o de cualesquiera otros datos o circunstancias de los que tenga conocimiento, decida modificar, al amparo del artículo $40 \mathrm{LC}$, el régimen de intervención por el de sustitución de facultades ${ }^{5}$. Incluso en ocasiones es la propia Administración Concursal la que solicita esta modificación del régimen de facultades a causa de la evolución del concurso ${ }^{6}$.

\footnotetext{
${ }^{2}$ A pesar de que la regla general prevista en los artículos 40.1 y 40.2 LC es establecer el régimen de intervención de las facultades del concursado por parte de la Administración Concursal en los supuestos de concursos voluntarios y el de suspensión de facultades en los concursos necesarios, conviene destacar la previsión contenida en el artículo 40.3 LC respecto a la posibilidad que ostenta el Juez para modificar mencionada regla. En relación a los criterios judiciales que pueden amparar esta decisión, vid. MORENO SERRANO, E., «La aplicación del artículo 40 LC en la jurisprudencia (La intervención o suspensión de las facultades patrimoniales del órgano de administración de las sociedades de capital en concurso)», Revista de Derecho Concursal y Paraconcursal, $\mathrm{n}^{\circ}$ 8, Primer semestre de 2008, p. 33, donde se usa como ejemplo el concurso de la Unión Deportiva Las Palmas S.A.D para ilustrar la posibilidad de modificar el régimen de intervención por el de suspensión de las facultades del deudor.

${ }^{3}$ La Ley 10/1990, de 15 de octubre, del Deporte define en su artículo 13 a los clubes deportivos como las asociaciones privadas, integradas por personas físicas o jurídicas que tengan por objeto la promoción de una o varias modalidades deportivas, la práctica de las mismas por sus asociados, así como la participación en actividades y competiciones deportivas.

${ }^{4}$ Vid. Auto Juzgado de lo Mercantil n ${ }^{\circ} 1$ de Las Palmas de Gran Canaria de 5 de noviembre de 2004 (proc. 6/2004, concurso Unión Deportiva Las Palmas S.A.D) en el que se establece que la actividad de la entidad concursada, dada su naturaleza fundamentalmente deportiva, centrada, además, en un deporte altamente profesionalizado como es el fútbol, presenta una serie de especialidades y peculiaridades que exceden de las habituales en otras empresas y sociedad mercantiles. Ello aconseja que, al menos de momento, sigan siendo los actuales administradores quienes continúen llevando la gestión ordinaria del club.

${ }^{5}$ Precisamente y como continuación a la nota inmediatamente precedente, es en el Auto del Juzgado de lo Mercantil n ${ }^{\circ} 1$ de Las Palmas de Gran Canaria de 13 de enero de 2005 (proc. 6/2004) en el que, tras haber acordado en un primer momento la intervención de las facultades del deudor, se acuerda revocar las mismas, pasando del régimen de intervención al de sustitución de facultades a la vista del escrito presentado por los administradores concursales.

${ }^{6}$ Vid. Auto Juzgado de lo Mercantil n ${ }^{\circ} 2$ de La Coruña de 11 de diciembre de 2013 (proc.16/2013, concurso Real Club Deportivo de la Coruña S.A.D) en el que se acuerda pasar del régimen de
} 
Para ello, debe tomarse como referencia el artículo 33.1.b.13 ${ }^{\circ} \mathrm{LC}$ que es el encargado de señalar las funciones que asume la Administración Concursal cuando las facultades del deudor son intervenidas, correspondiendo a ésta entre otras la labor de determinar los actos u operaciones propios del giro o tráfico que por ser necesarios para la continuidad de la actividad, quedan autorizados con carácter general ${ }^{7}$.

En esta situación, la Administración Concursal debe marcar los límites en los que se puede mover la actuación del órgano directivo de la entidad y distinguir entre aquellas decisiones que suponen la mera gestión del club con aquellas que sean actos de administración y disposición que requieran autorización particular y no la genérica propia de los actos de gestión ${ }^{8}$.

En este punto es interesante realizar una reflexión respecto a si la contratación de jugadores o la venta de parte de la plantilla constituye un acto de gestión del club (recordemos que su fin es la participación en competiciones deportivas) y que por tanto puede ser acometido por el deudor sin necesidad de autorización o si por el contrario nos encontramos ante una decisión que por su trascendencia patrimonial precisa de autorización específica por parte de la Administración Concursal. Nos decantamos por ésta última al compartir la idea relativa a que la contratación de jugadores constituye un acto de disposición de la institución deportiva muy importante (probablemente el más relevante que realiza ésta) el cual conlleva un compromiso económico que vincula al club en las sucesivas temporadas y que precisa de la autorización particular de la Administración Concursal ${ }^{9}$.

\section{Suspensión de las facultades de la entidad deportiva.}

Una mayor problemática presentan aquellas situaciones en las que las facultades del deudor son suspendidas, teniendo que ser la Administración Concursal quien tome directamente las decisiones que aseguren la continuidad de la entidad deportiva en

intervención de facultades al de suspensión de las mismas exclusivamente en cuanto a la formulación de las cuentas a petición de la Administración Concursal. Es interesante esta resolución por cuanto el Juzgado establece que la suspensión refleja un riesgo evidente: la gestión de una sociedad anónima deportiva es una labor compleja que requiere de conocimientos especializados (...) Además, enero es periodo de fichajes y dejar esas importantes decisiones en manos de la administración concursal sería irresponsable.

${ }^{7}$ Vid. la crítica que efectúa el profesor YANES YANES al Auto del Juzgado de lo Mercantil $\mathrm{n}^{\circ} 1$ de Las Palmas de Gran Canaria de 5 de noviembre de 2004 (proc. 6/2004) encargado de declarar el concurso de la Unión Deportiva Las Palmas S.A.D y al que hacíamos referencia en las notas precedentes, por contener una serie de decisiones tomadas por el Juez (continuidad del entrenador) con carácter previo al nombramiento de la Administración Concursal y que podrían ser distorsionadoras del reparto de poderes entre el Juez y la Administración Concursal establecido en la Ley Concursal. Vid. YANES YANES, P., «Comentario de urgencia al Auto que declara en concurso a la «Unión Deportiva Las Palmas, S.A.D», Revista de Derecho Concursal y Paraconcursal, $n^{\circ}$ 2/2005, Primer semestre de 2005.

${ }^{8}$ Vid. a efectos meramente ejemplificativos Sentencia AP Barcelona (Sección 15 a) de 9 de junio de 2015 (Rollo 565/2014) en la que se ampara las autorizaciones impartidas por parte de la Administración Concursal a la concursada por recaer las mismas dentro de sus competencias.

9 Vid. Sentencia AP Palma de Mallorca de 11 de febrero de 2016 (Recuso 343/2015) en el seno del concurso del Real Club Deportivo Mallorca en la que se recoge la forma inicial de trabajo de la Administración Concursal mediante autorizaciones genéricas suspendida cautelarmente respecto a la contratación de jugadores para no permitir más desembolsos. 
concurso de conformidad con el artículo 44.3 LC. De esta forma, la Administración Concursal se convierte en el órgano que sustituye al deudor en la adopción de decisiones empresariales ${ }^{10}$.

En la generalidad de los concursos, las decisiones que debe tomar la Administración Concursal estarán reducidas al estricto ámbito económico, pero en el caso de sociedades deportivas, además de la situación económica, debe tenerse en cuenta el componente deportivo, lo que coloca en una difícil situación al órgano concursal. Esta complejidad se pone especialmente de manifiesto cuando nos encontramos ante el régimen de suspensión de facultades del deudor, provocando que sea el órgano de la Administración Concursal quien tome la iniciativa en las decisiones, posición mucho más complicada si se compara con aquellas situaciones donde las facultades del deudor únicamente son intervenidas, casos en los que ésta sólo se limita a autorizar lo que se le propone.

Todo ello sin perjuicio de que, conforme al artículo 48.1 LC, los órganos sociales de la persona jurídica en concurso sigan existiendo aun sin facultades de administración y disposición ${ }^{11}$ (las cuales, como hemos indicado, pasarán a ser ejercidas por la Administración Concursal) circunstancia que en ocasiones puede generar ciertos conflictos de competencia ${ }^{12}$.

En todo caso, el parámetro de diligencia ${ }^{13}$ exigible a la Administración Concursal en el desempeño de su cargo conforme a lo establecido en el artículo $35 \mathrm{LC}$, requiere que ésta se asesore convenientemente del director deportivo o del cuerpo técnico del club para acometer con acierto las decisiones estrictamente deportivas ${ }^{14}$.

${ }^{10}$ Vid al respecto CORDÓN MORENO, F., «Comentario art. 44» en CORDÓN MORENO, F., (Dir.) Comentarios a la Ley Concursal, Thomson Reuters Aranzadi, Navarra, 2010, $2^{\mathrm{a}}$ edición, tomo I, p.522, quien destaca que nada dice la Ley respecto al contenido de las medidas que la Administración Concursal puede adoptar, las cuales deberán responder al principio de conservación establecido en el artículo 43 LC.

${ }^{11}$ Vid. la completa exposición que se efectúa respecto a la relación entre los órganos de la persona jurídica concursada y los órganos del concurso en QUIJANO GONZÁLEZ, J., «La administración concursal» en PULGAR EZQUERRA. J., (Dir.) El Concurso de Acreedores, La Ley, Madrid, 2012, p. 235 quien destaca cómo los órganos de la persona jurídica mantienen su estructura, composición, funciones $\mathrm{y}$ atribuciones $\sin$ perjuicio de los efectos que sobre su funcionamiento produzca la intervención o la suspensión de sus facultades de administración o disposición.

12 En igual sentido MORALEJO MENÉNDEZ, I., «La administración concursal» en GARCÍACRUCES, J.A., (Dir.) Jurisprudencia y Concurso, Tirant lo Blanch, Valencia, 2017, p. 162 y 163.

${ }^{13}$ El artículo 1.104 del Código Civil define el deber de diligencia como el comportamiento que exija la naturaleza de la obligación y corresponda a las circunstancias de las personas, del tiempo y lugar, y sólo en caso de que la obligación no exprese la diligencia que ha de prestarse en su cumplimiento, se exigirá la correspondiente a la de un buen padre de familia. SÁNCHEZ ARISTI. R «Comentario art. 1.104» en BERCOVITZ RODRÍGUEZ-CANO, R., (Coord.) Comentarios al Código Civil, Aranzadi, Navarra, 2001, p. 1284, señala que la diligencia del buen padre de familia, más que un modelo singular, se erige en la clase de todos los modelos de diligencia prestable, atendidas en cada caso la naturaleza de la obligación y las circunstancias de persona, tiempo y lugar. Añade el autor que el segundo apartado del artículo 1.104 $\mathrm{CC}$ admite que la obligación exprese otro modelo de diligencia, pactado por las partes, es decir la exigibilidad de un estándar diferente.

14 Vid. MUÑÓZ DE BENAVIDES, C., «La responsabilidad de los administradores concursales», Diario La Ley, $\mathrm{n}^{\circ}$ 7522, 2 Dic. 2010, Año XXXI, Ref. D-369, quien señala que la diligencia exigible es superior a la de un administrador social, puesto que el administrador concursal es un profesional nombrado legalmente por su especial cualificación para desarrollar una importante y compleja tarea, mientras que el administrador social es nombrado de acuerdo a las reglas del libre comercio y sus decisiones, más allá de 


\section{Decisiones que debe adoptar la Administración Concursal para garantizar la continuidad de la actividad de la entidad deportiva.}

Una vez determinada la posición en la que se encuentra la Administración Concursal dependiendo de si las facultades del deudor en concurso se encuentran suspendidas o meramente intervenidas, realizamos a continuación una reflexión respecto a las medidas que deben afrontarse en el concurso de una institución de estas características para conseguir que la misma siga con su actividad económica, la cual, como ya hemos señalado, se encuentra directamente relacionada con su objeto social de participación en competiciones deportivas.

La LC propugna como uno de sus principios esenciales la continuidad de la actividad del deudor - apartado VII de la Exposición de Motivos LC-. De igual forma, el artículo $44 \mathrm{LC}$ establece que la declaración de concurso no interrumpe la actividad empresarial o profesional que viniera éste ejerciendo. Por lo tanto, salvo en supuestos en los que la situación de la entidad deportiva conlleve inevitablemente su liquidación y su consiguiente desaparición, la Administración Concursal debe proponer las medidas necesarias para que la misma pueda seguir compitiendo.

Estas medidas serán en su mayoría decisiones de índole económica; sin embargo, afectarán directamente a la actividad deportiva, por lo que deberán tomarse previo análisis de su repercusión en referida parcela. De esta forma, la Administración Concursal, para intentar garantizar la supervivencia y viabilidad del club en concurso, deberá adoptar decisiones relacionadas con el salario de los deportistas o la compra y venta de fichas de jugadores, medidas esencialmente económicas pero con un impacto deportivo directo en la institución.

Como decimos, normalmente, las primeras decisiones que se asumen suelen estar relacionadas con la reducción de la retribución a percibir por los jugadores integrantes de la plantilla. La razón de ello es que en las entidades deportivas profesionales, los salarios suelen ser muy sustanciales, constituyendo una importante carga económica para el club que compromete la viabilidad financiera del mismo. Ello provocará casi con toda probabilidad un enfrentamiento entre la Administración Concursal y los deportistas que el órgano concursal debe solventar para asegurar el rendimiento de la misma en beneficio del proyecto deportivo ${ }^{15}$.

Todas estas decisiones vienen presididas normalmente por la austeridad como patrón de conducta de la actuación de la Administración Concursal. No es que la austeridad deba ser por capricho el principio que presida la actuación de este órgano en su función al

si son acertadas o no, deben entenderse en este contexto (a diferencia del administrador concursal quien debe ser mucho más conservador en sus decisiones, ajustándose en todo caso al marco legal que preside su actuación).

${ }^{15}$ Vid. Sentencia AP Madrid (Sección 28a) de 16 de enero de 2015 (Rec. 60/2013) por la que se resuelve estimar el recurso presentado por un futbolista de la plantilla del Rayo Vallecano de Madrid S.A.D y consecuentemente revocar parcialmente la Sentencia de Instancia que a su vez había acogido la Demanda formulada por la Administración Concursal con la pretensión de reducir su salario por ser el contrato suscrito con el club perjudicial para los intereses de la masa. 
frente - $\mathrm{o}$ al lado si las facultades del deudor solo han sido intervenidas - de la entidad deportiva, sino que normalmente es la única vía para poder conservar la actividad del deudor.

No debe olvidarse que la declaración de concurso se produce cuando el deudor no puede cumplir regularmente sus obligaciones exigibles. Llegados a este punto, cuando la situación se judicializa, habitualmente ya existen deudas acumuladas con proveedores, lo que supone que la Administración Concursal no sólo deba organizar el pago del pasivo exigible, sino que debe también ir abonando las deudas atrasadas del club, además de afrontar el pago de los créditos a los que ha podido recurrir la institución en la época preconcursal, obligaciones todas ellas a las que se tiene que ir haciendo frente conforme se intenta que el club siga hacia adelante. A ello debe sumarse la mencionada especialidad del objeto social del concursado, circunstancia que provoca que la Administración Concursal deba ser extremadamente prudente a la hora de tomar sus decisiones, al carecer de los conocimientos deportivos necesarios para acometer determinadas operaciones.

Todo ello debe ponerse en consonancia con el artículo $43 \mathrm{LC}$ que establece el principio de conservación y administración de la masa activa del modo más conveniente para los intereses del concurso - es decir, para el interés de los acreedores-.

A veces, el choque entre las decisiones económicas y las deportivas es inevitable y es ahí donde la Administración Concursal debe escoger qué es lo mejor para la viabilidad de la entidad. El fin que debe presidir sus decisiones debe ser el beneficio de los acreedores, el cual normalmente va anudado a la buena marcha deportiva de la institución. Situaciones como oportunidades de incorporación de deportistas que podrían ayudar a la consecución de los objetivos del club deben ser desechadas si comprometen la situación económica de la misma o si supone un riesgo demasiado alto que pudiera perjudicar el interés de los acreedores. De igual forma, la venta de determinadas fichas de jugadores integrantes de la plantilla puede ser un importante ingreso económico para el deudor, circunstancia que el órgano concursal deberá valorar en relación a la pérdida de potencial deportivo de la institución.

Es importante destacar que en ocasiones, el elemento deportivo es el que puede hacer salir al deudor de la situación de crisis en la que se encuentra. Los ingresos de las entidades deportivas dependen mucho de la categoría en la que compitan. Un ascenso de categoría puede atraer a más aficionados, patrocinadores y en su caso contratos televisivos que supondrán una importante inyección económica ${ }^{16}$. Por el contrario, en otras ocasiones el club no tiene capacidad real para competir en un nivel superior al que ya lo está haciendo, situación en la que puede ser más conveniente mantener la categoría y no acometer inversiones demasiado arriesgadas.

\footnotetext{
${ }^{16}$ Respecto a los contratos suscritos por el deudor, vid. SANJUÁN Y MUÑOZ. E; «El proyecto de reforma concursal y las entidades deportivas. Crítica a la Disposición adicional segunda bis», Revista de Derecho Concursal y Paraconcursal, $\mathrm{n}^{\mathrm{0}}$ 15, Segundo semestre de 2011, quien señala que el régimen de actuación del concursado se sujeta a lo previsto en los artículos 40 y 44 LC, sin que se prevea ninguna intervención específica de otro órgano diferente a la Administración Concursal.
} 
Tampoco puede dejar de tomarse en consideración el elemento sentimental que las instituciones deportivas producen en sus aficionados, lo que puede aconsejar invertir en políticas que atraigan abonados para apoyar al equipo más que en la contratación de los derechos deportivos de nuevos integrantes que refuercen la plantilla con la que se cuenta.

Todas éstas son circunstancias que tendrá que valorar la Administración Concursal, decisiones deportivas a las que van anudadas inevitablemente consecuencias económicas.

Junto a ellas, la Administración Concursal debe tomar decisiones que protejan el patrimonio de la entidad concursada, como son el ejercicio de las acciones previstas en el artículo 71 LC — acciones de reintegración - para deshacer determinados actos que pudiesen ser perjudiciales para el patrimonio del deudor (lo que puede ser un nuevo foco de conflicto en aquellas ocasiones en las que mencionados acuerdos tienen como protagonistas a personas que integran la propia institución) o aquellas orientadas a proteger al club respecto a decisiones de órganos federativos externos al mismo que busquen imponerle sanciones que puedan comprometer la viabilidad económica del proyecto $^{17}$.

\section{Confección del informe de los artículos 74 y 75 de la Ley Concursal.}

Los artículos 74 y 75 LC son los encargados de regular el plazo de confección -74 LC - y el contenido - 75 LC - del informe que la Administración Concursal debe elaborar respecto a la situación patrimonial pasada, presente y futura del deudor en concurso.

En los concursos de entidades deportivas, la Administración Concursal se enfrenta a la confección de un informe donde, además de exponer los datos puramente económicos de la gestión de la institución, cobra una gran importancia el análisis relativo al grado de influencia que ha tenido el rendimiento deportivo en la capacidad económica del club. $\mathrm{Y}$ es que determinados acontecimientos como el descenso o el ascenso de categoría deportiva influyen de forma muy relevante en la situación económica de la institución por la directa relación que ello tiene con ingresos fundamentales para el club como es la venta de entradas, los derechos de retransmisión o la publicidad ${ }^{18}$.

De igual forma, debe observarse que, a pesar de la declaración de concurso, las entidades deportivas continúan sometidas a la normativa reguladora de cada una de las competiciones en las que participa, así como a la Ley 10/1990, de 15 de Octubre, del Deporte, extremo que debe ser reflejado por la Administración Concursal en el informe

\footnotetext{
${ }^{17}$ Como muestra, vid. Auto del Juzgado de lo Mercantil n ${ }^{\circ} .1$ de Granada de 21 de julio de 2011 (proc. 216/2011) en el seno del concurso del Club Baloncesto Granada S.A.D por el que se accede a la solicitud de la Administración Concursal de impedir la ejecución de un laudo arbitral de la FIBA cuya sanción bloquea la actividad de la concursada de cara a la siguiente temporada.

${ }^{18} \mathrm{Vid}$. aquí el análisis comparativo que en relación a la importancia de los resultados deportivos realizan PASCUAL. M, VEGA. P., «Análisis de los principales indicadores de insolvencia empresarial en los equipos de fútbol de primera división española» en BELTRÁN. E, PALOMAR OLMEDA. A (Dirs.) $L a$ insolvencia de las entidades deportivas profesionales, Thomson Reuters Aranzadi, Navarra, 2012, p. 153 y 154.
} 
a la hora de explicar determinadas decisiones que han podido adoptarse y que condiciona el comportamiento de los clubes deportivos. El principal condicionante ha venido estando constituido por la Disposición Adicional Segunda bis LC, que en su redacción vigente establece el sometimiento de las entidades deportivas que participen en competiciones oficiales a la legislación del deporte ${ }^{19}$.

Así mismo - conforme se adelantaba en el epígrafe anterior- la Administración Concursal deberá hacer referencia a aquellos actos que el club haya realizado en los dos años anteriores a la declaración de concurso y que pudiera ser considerado perjudicial para su patrimonio, en cuyo caso sería necesario ejercitar las correspondientes acciones de reintegración (71 LC) para anularlos ${ }^{20}$. De hecho no son infrecuentes los casos en los que, ante la inminencia de la declaración de concurso, los clubes adoptan determinadas decisiones como puede ser la renovación de jugadores ${ }^{21}$ o la firma de acuerdos ${ }^{22}$, actos todos ellos que, al haberse realizado en el periodo de dos años anteriores a la declaración de concurso, serán revisados por parte de la Administración Concursal por si los mismos se hubiesen efectuado en perjuicio de los acreedores.

\section{Convenios suscritos por las entidades deportivas.}

Salvo contadas excepciones, en la mayoría de los concursos de acreedores de entidades deportivas se alcanza un acuerdo con los acreedores ${ }^{23}$. No puede dejar de mencionarse en este sentido el importante peso que en ellos tiene el elemento sentimental y la

\footnotetext{
${ }^{19}$ Ello ha tenido una gran importancia en el mundo del fútbol, donde el artículo 192 del Reglamento general de la Real Federación Española de Fútbol prevé el descenso de categoría para aquellos clubes que no cumplan con determinadas obligaciones económicas, normativa que colisiona con la Ley Concursal, que aboga por que el deudor concursado continúe su actividad económica en iguales condiciones para poder salir de la situación de crisis en la que se encuentra.

${ }^{20}$ El concepto de perjuicio en relación a las acciones de reintegración ha sido ampliamente tratado por la doctrina concursalista. Destacamos a LEÓN, F., "Comentario art. 71» en ROJO, A., BELTRÁN, E., Comentario de la Ley Concursal, Civitas, Madrid, 2004, tomo I. p.1307, quien señala que existe perjuicio cuando el acto impugnado impida, disminuya o dificulte la satisfacción colectiva de los acreedores concursales. Para SILVETTI, E., «Comentario art. 71» en CORDÓN MORENO, F; (Dir.) Comentarios a la Ley Concursal, Thomson Reuters Aranzadi, Navarra, 2010, 2 a edición, p. 804, el perjuicio es todo acto que suponga una disminución patrimonial de la masa del deudor sin que venga acompañado por un incremento patrimonial, con las precisiones establecidas por la doctrina y la Jurisprudencia. GIL RODRÍGUEZ, J., «Comentario art. 74» en BERCOVITZ RODRÍGUEZ-CANO, R., (Coord.) Comentarios a la Ley Concursal, Tecnos, Madrid, 2004, p.852 determina que el perjuicio común suele considerarse que concurre desde el momento en el que el acto en cuestión ha acarreado una disminución del patrimonio realizable del deudor o ha provocado una alteración injustificada de las preferencias de cobro que pudieran corresponder a los acreedores concurrentes.

${ }^{21}$ Vid. Sentencia Juzgado de lo Mercantil no 3 de Madrid de 26 de julio de 2012 (Proc. 905/2011) en la que se acuerda en el procedimiento concursal del Rayo Vallecano de Madrid S.A.D anular a instancia de la Administración Concursal el contrato de renovación de un jugador de la plantilla por constituir un acto perjudicial para la masa activa del club concursado.

${ }^{22}$ En relación a ello, vid. Sentencia Audiencia Provincial de Álava (Sección 1 ${ }^{\text {a }}$ ) de 9 de febrero de 2012 (Rec.508/2011) en virtud de la cual se acuerda mantener la declaración de reintegrables a la masa de una serie de actos de disposición realizados por el club concursado (Deportivo Alavés S.A.D) consistentes en el pago de servicios profesionales deportivos en el periodo de dos años previos a la declaración de concurso.

${ }^{23}$ La última entidad deportiva de renombre en desaparecer ha sido la Unión Deportiva Salamanca, tras no poder alcanzarse un acuerdo entre los acreedores en fase de convenio.
} 
vinculación del club con el lugar geográfico donde compite, lo que provoca una importante predisposición al pacto, amparado además por la colaboración de las instituciones públicas del lugar ${ }^{24}$.

Todo ello no es baladí, ya que originariamente y hasta el año 2014, en sede de fase de convenio el texto concursal preveía en el segundo párrafo de su artículo 100.1 LC la posibilidad de superar una quita del 50\% y una espera de cinco años cuando se tratara de concursos de empresas cuya actividad pudiera tener especial transcendencia para la economía. Demostrar esta trascendencia era por tanto fundamental para alcanzar un convenio que permitiese elevadas quitas y dilatadas esperas, allanando así el camino de recuperación de la institución deportiva.

A pesar de que referido dato ha dejado de ser considerado legalmente para la adopción de acuerdos, sigue conservando mucha importancia a la hora de afrontar la negociación los efectos económicos que la entidad deportiva tiene para el lugar donde la misma compite, ya que la localización geográfica de la misma en un determinado sitio, provoca sustanciales ingresos para el sector hotelero, la restauración y el comercio, además de la propia promoción de la ciudad en la que la institución deportiva se encuentra ubicada ${ }^{25}$.

Estos datos permiten a la Administración Concursal adoptar una postura más reforzada de cara a la negociación de un convenio que permita la colaboración de la Administración Pública. De hecho los efectos económicos para la ciudad en la que se encuentra situada la entidad deportiva junto al elemento sentimental, suelen ser armas muy eficaces para conseguir de las autoridades públicas el apoyo necesario en busca de la viabilidad de la continuación de la actividad del club.

\section{La liquidación de las entidades deportivas.}

Como continuación a lo expuesto en el epígrafe inmediato anterior, también existen situaciones donde el club no puede seguir adelante, viéndose la Administración Concursal obligada a plantear las operaciones necesarias para su liquidación.

En esta situación, la liquidación del patrimonio de la entidad se realizará conforme a lo establecido en los artículos 142 y siguientes LC, adquiriendo gran relevancia la labor de

\footnotetext{
${ }^{24}$ De hecho, en ocasiones la falta de apoyo por parte de las instituciones del lugar es lo que aboca al club al concurso. Vid en este sentido la Sentencia de la Audiencia Provincial de León (Sección 1a) de 27 de enero de 2014 (rec. 314/2013) en el seno del concurso del Baloncesto León S.A.D, en la que se recoge como causa de la situación de insolvencia de la entidad, entre otras, la falta de apoyo de las instituciones públicas con su subvención y patrocinio, lo que provoca que caiga la fuente de financiación de las actividades de la concursada.

${ }^{25}$ La imagen de la ciudad se ve beneficiada de forma importante, tanto a nivel nacional como internacional - dependiendo de la relevancia de la institución deportiva- ya que aumenta el conocimiento y localización de la misma, lo que consecuentemente conlleva un incremento del turismo y la inversión. Nos remitimos respecto a este particular al estudio efectuado por la Cámara de Comercio de Zaragoza en octubre de 2009 respecto al impacto económico que supone para la ciudad que el Real Zaragoza compita en la $1^{\text {a }}$ división de fútbol español.
} 
la Administración Concursal en relación al plan de liquidación que ésta debe presentar al Juez del Concurso - artículo 148 LC_ ${ }^{26}$.

De conformidad con el contenido del artículo 148 LC, siempre que sea factible, deberá intentarse la enajenación unitaria del club para conseguir que el mismo simplemente cambie de dirección pero pueda seguir compitiendo. La Administración Concursal deberá apostar por ello y solo en caso de que no sea posible, acudir a otras fórmulas como es la venta individual de bienes y derechos.

Las particularidades que presenta la liquidación de los bienes y derechos de una institución deportiva son diversas. Normalmente su principal activo suele ser el centro deportivo donde disputa los partidos como local, pero también lo forman muchos otros como los derechos de retransmisión, los derechos federativos ${ }^{27}$, los trofeos conquistados o los propios jugadores.

\section{Fase de calificación.}

Por último y con independencia de la solución del procedimiento, los artículos $163 \mathrm{y}$ siguientes regulan todo lo relativo a la calificación del concurso. Como señala el artículo 167.1 LC, para que se produzca la apertura de la sección de calificación, no puede haberse aprobado un convenio en el que se prevea una quita inferior a un tercio o una espera inferior a tres años, salvo que el mismo resulte incumplido. Ello provoca que esta sección suela abrirse normalmente en los concursos de estas entidades, ya que lo habitual es que se superen dichos límites ${ }^{28}$.

Conforme a lo establecido en el artículo 169 LC, en el informe que presente la Administración Concursal respecto a este particular, deberá exponer entre otros extremos qué conductas de las que ha podido presenciar pueden constituir dolo o culpa grave de los administradores de la institución deportiva en concurso o las anomalías que haya podido detectar en la documentación que se le ha facilitado ${ }^{29}$.

\footnotetext{
${ }^{26}$ En relación a este documento, vid. entre otros muchos RUBIO VICENTE, P.J., «La liquidación concursal» en PULGAR EZQUERRA. J., (Dir.) El Concurso de Acreedores, La Ley, Madrid, 2012, p. 480 y ss.

${ }^{27}$ Vid. Auto AP Salamanca de fecha 25 de julio de 2014 (Rec.140/2014) en el seno del concurso de la Unión Deportiva Salamanca en la que se recoge la posibilidad de transmisión de referido derecho dado el indiscutible valor económico que ostenta el mismo y al haber sido efectuada la transmisión conforme al artículo 43 LC. Rechaza la Sala que la venta de los derechos federativos encubra una indebida sucesión de empresa ya que la inscripción de los mismos por sí solos no son suficientes para el desarrollo de la actividad empresarial.

${ }^{28}$ Vid. Sentencia AP Baleares (Sección 5a) de 14 de enero de 2013 (Rollo 473/2012) en la que se rechaza la apertura de la fase de calificación al ser el plazo de espera establecido en el convenio inferior a tres años.

${ }^{29}$ Llama la atención el argumento simple y claro utilizado por la Audiencia Provincial de Guipúzcoa en el concurso de la Real Sociedad Club de Fútbol para confirmar la declaración de concurso culpable del club. Vid. Sentencia Audiencia Provincial de Guipúzcoa (Sección 2a) de 29 de julio de 2011 (Rec.2123/2011): En este supuesto, hay que partir de que, en puridad, una sociedad mercantil que gasta más de lo que puede en una situación dificil como en la que se encontraba la concursada a finales de dos mil siete y primeros de dos mil ocho, haciendo importantes desembolsos para fichar juzgadores, está agravando de forma consciente su situación económica y coadyuvando a lo que pasó pocos meses después, la solicitud de concurso.
} 
Habitualmente, este tipo de clubes deportivos no han venido siendo gestionados por profesionales, sino por personas procedentes de otros sectores, lo que explica prácticas de gestión negligentes que la Administración Concursal debe poner de referencia en este momento, sin perjuicio de lo que haya podido recoger en su informe de los artículos 74 y $75 \mathrm{LC}^{30}$.

Además, suscita una importante reflexión que no puede perderse de vista el hecho de que los socios del club no esperan que los directivos consigan resultados económicos que generen dividendos, sino que lo que buscan son resultados deportivos que lleven al club a conseguir sus objetivos. Ello explica determinados comportamientos de los gestores de la entidad, como son los endeudamientos injustificados en busca de metas deportivas más o menos verosímiles ${ }^{31}$.

\section{Conclusiones.}

La declaración de concurso de una persona jurídica cuyo objeto social es la participación en competiciones deportivas conlleva determinadas singularidades que provoca un importante esfuerzo en el órgano de la Administración Concursal para dar cumplimiento al mandato del legislador contenido en el artículo $21.1 .2^{\circ} \mathrm{LC}$.

Singularidad porque el deudor no sólo está sometido a la LC, sino también a la Ley del deporte y resto de normativa deportiva, lo que provoca en ocasiones el choque entre unas y otras normativas.

Particularidad por lo especial de la actividad del deudor, lo que provoca en los supuestos de suspensión de facultades, la Administración Concursal tenga que tomar decisiones deportivas para las que normalmente no está preparada.

Peculiaridad también derivada del componente social que toda entidad deportiva lleva consigo, lo que influye en determinadas decisiones o negociaciones que puedan producirse en el marco de la gestión del club.

Todo ello abunda en lo expuesto en el presente estudio. La función de la Administración Concursal en la gestión de la insolvencia de un deudor de estas características exige una

\footnotetext{
${ }^{30}$ Como nos recuerdan ARNALDO ALCUBILLA y FUENTES ARJONA, existe la posibilidad de que los administradores de la entidad deportiva respondan incluso penalmente. Vid. ARNALDO ALCUBILLA, E; FUENTES ARJONA, T., «La responsabilidad de los administradores de la sociedad anónima deportiva» en GUERRA MARTÍN, G., (Coord.) La responsabilidad de los administradores de sociedades de capital, La Ley, Madrid, 2011, quienes se hacen eco de la Sentencia de la Sala de lo Penal del Tribunal Supremo de 4 de junio de 2004 (Rec.846/2003) relativa a la condena a varios directivos del Club Atlético de Madrid S.A.D por estafa.

${ }^{31}$ Volvemos a tomar como referencia el concurso de la Real Sociedad Club de Fútbol para destacar la Sentencia del TS de 24 de mayo de 2013 (Rec.2323/2011) en el que se confirma la Sentencia de la Audiencia Provincial de San Sebastián respecto a la calificación como culpable del concurso del club por superación de los gastos presupuestados. La resolución del Alto Tribunal señala firmemente que el acuciante deseo de obtener éxitos en el campeonato - con la contratación de nuevos futbolistas - no puede explicar las desviaciones presupuestarias, tanto más si es notorio que los buenos resultados deportivos no son incompatibles con un diligente rigor en dicha materia.
} 
especial diligencia por su parte al no estar preparada para asumir la carga discrecional que en ocasiones conlleva el ejercicio de una actividad tan particular como es la dirección deportiva de un club profesional. Ello exige una referencia específica en la LC a este tipo de procedimientos mediáticos, que debería venir motivada por requerir que en mencionados procedimientos, el profesional designado tuviese preparación específica en materia deportiva o el auxilio de profesionales independientes que dispusiesen de ella.

Para evitar las situaciones que se han provocado en la práctica, sería necesario la existencia de un órgano de supervisión de la situación económica de los clubes que impidiera que en el supuesto de que los mismos se vean abocados a la declaración de concurso, la Administración Concursal se encuentre con entidades prácticamente ahogadas por sus propias deudas y sin margen de maniobra alguno para reflotarla, sino es por el sacrificio de los acreedores y la intervención de los poderes públicos.

\section{Bibliografía.}

-ARNALDO ALCUBILLA, E; FUENTES ARJONA, T., «La responsabilidad de los administradores de la sociedad anónima deportiva» en GUERRA MARTÍN, G., (Coord.) La responsabilidad de los administradores de sociedades de capital, La Ley, Madrid, 2011.

-CORDÓN MORENO, F., «Comentario art. 44» en CORDÓN MORENO, F., (Dir.) Comentarios a la Ley Concursal, Thomson Reuters Aranzadi, Navarra, 2010, $2^{\text {a }}$ edición, tomo I.

-GIL RODRÍGUEZ, J., «Comentario art. 74» en BERCOVITZ RODRÍGUEZ-CANO, R., (Coord.) Comentarios a la Ley Concursal, Tecnos, Madrid, 2004.

-LEÓN, F., "Comentario art. 71» en ROJO, A., BELTRÁN, E., Comentario de la Ley Concursal, Civitas, Madrid, 2004, tomo I.

-MORALEJO MENÉNDEZ, I., «La administración concursal» en GARCÍA- CRUCES, J.A., (Dir.) Jurisprudencia y Concurso, Tirant lo Blanch, Valencia, 2017.

-MORENO SERRANO, E., «La aplicación del artículo 40 LC en la jurisprudencia (La intervención o suspensión de las facultades patrimoniales del órgano de administración de las sociedades de capital en concurso)», Revista de Derecho Concursal y Paraconcursal, nº 8, Sección Comunicaciones, Primer semestre de 2008.

-MUÑ́́Z DE BENAVIDES, C., «La responsabilidad de los administradores concursales», Diario La Ley, $\mathrm{n}^{\circ}$ 7522, Sección Tribuna, 2 Dic. 2010, Año XXXI, Ref. D-369.

-PALOMAR OLMEDA, A., «La insolvencia de las entidades deportivas profesionales» en CAMPUZANO, A., SANJUÁN Y MUÑOZ, E., (Dirs.) El Derecho de la Insolvencia, Tirant lo Blanch, Valencia, 2016. 
-PASCUAL. M, VEGA. P., «Análisis de los principales indicadores de insolvencia empresarial en los equipos de fútbol de primera división española» en BELTRÁN. E, PALOMAR OLMEDA. A (Dirs.) La insolvencia de las entidades deportivas profesionales, Thomson Reuters Aranzadi, Navarra, 2012.

-QUIJANO GONZÁLEZ, J., «La administración concursal» en PULGAR EZQUERRA. J., (Dir.) El Concurso de Acreedores, La Ley, Madrid, 2012.

-RUBIO VICENTE, P.J., «La liquidación concursal» en PULGAR EZQUERRA. J., (Dir.) El Concurso de Acreedores, La Ley, Madrid, 2012.

-SÁNCHEZ ARISTI. R «Comentario art. 1.104» en BERCOVITZ RODRÍGUEZCANO, R., (Coord.) Comentarios al Código Civil, Aranzadi, Navarra, 2001.

-SANJUÁN Y MUÑOZ. E; «El proyecto de reforma concursal y las entidades deportivas. Crítica a la Disposición adicional segunda bis», Revista de Derecho Concursal y Paraconcursal, $\mathrm{n}^{\mathrm{o}}$ 15, Sección Comunicaciones, Segundo semestre de 2011.

-SILVETTI, E., «Comentario art. 71» en CORDÓN MORENO, F; (Dir.) Comentarios a la Ley Concursal, Thomson Reuters Aranzadi, Navarra, 2010, $2^{\mathrm{a}}$ edición.

-YANES YANES, P., «Comentario de urgencia al Auto que declara en concurso a la Unión Deportiva Las Palmas, S.A.D», Revista de Derecho Concursal y Paraconcursal, $n^{0}$ 2/2005, Sección Reseñas y comentarios de jurisprudencia, Primer semestre de 2005. 